\title{
Changes in the Lysosomal System of Cervical Cancer Cells Induced by Emodin Action
}

\author{
WOJCIECH TRYBUS ${ }^{1}$, TEODORA KRÓL ${ }^{1}$, EWA TRYBUS ${ }^{1}$, ANNA KOPACZ-BEDNARSKA ${ }^{1}$, \\ GRZEGORZ KRÓL ${ }^{2}$ and EWA KARPOWICZ ${ }^{1}$ \\ ${ }^{1}$ Department of Cell Biology and Electron Microscopy, Institute of Biology, \\ The Jan Kochanowski University, Kielce, Poland; \\ ${ }^{2}$ Faculty of Management, University of Warsaw, Warsaw, Poland
}

\begin{abstract}
Background: An example of plant-derived compounds that may be of great importance in oncological therapy is emodin. The aim of this study was to evaluate the range of changes in the lysosomal compartment of HeLa cervical cancer cells treated with emodin. Materials and Methods: Changes in the lysosomal compartment were evaluated using microscopic techniques. In order to evaluate the activity of lysosomal enzymes and the permeability of the lysosomal membrane, a spectrophotometric technique was employed. Results: Emodin induced significant changes in the lysosomal compartment, manifesting as an increase in the number of lysosomes, autophagic vacuoles and the activity of lysosomal hydrolases. Emodin exhibited cytotoxic activity against lysosomes through lysosomal membrane damage with possible leaks of lysosomal hydrolases into the cytoplasm. Conclusion: Emodin induces degradation processes and promotes the death of tumor cells through a mechanism that occurs with clear involvement of the lysosomal compartment.
\end{abstract}

A major problem in the treatment of cancer is the removal of cells able to development immunological, chemotherapeutic and radiotherapeutic resistance. Avoidance of apoptotic death by tumor cells is one of the major barriers to cancer treatment, as the action of many classic antitumor drugs is based on triggering caspases that mediate apoptotic cell death (1). Hence, in recent years, much attention has been paid to new strategies for treatment using non-apoptotic

Correspondence to: Wojciech Trybus, Department of Cell Biology and Electron Microscopy, Institute of Biology, The Jan Kochanowski University, Świętokrzyska 15, 25-406 Kielce, Poland. E-mail: wojciech.trybus@ujk.edu.pl

Key Words: Emodin, lysosomal system, autophagy, cathepsins, apoptosis, permeability of lysosomal membrane. mechanisms, i.e. autophagy, lysosomal cell death and necrosis, as they may be alternative mechanisms leading to cell death, including of cancer cells (2-4).

Anthraquinones, including emodin, the subject of our study, may be alternative agents in cancer therapy because they can induce cell death based on non-apoptotic mechanisms of action. Emodin (1,3,8-trihydroxy-6methylanthraquinone) was first isolated from extract of Rhamnus frangula L. (5). It has also been identified in the roots and rhizomes of many plant families such as Liliaceae (Aloe barbadensis Mill.) (6) and Polygonaceae (Rheum palmatum L., Rheum officinale B). Rheum officinale is used in traditional medicine, especially in Eastern Asia (7). Emodin has numerous pharmacological properties, including immunosuppressive (8), antibacterial (9), antifungal (10), antiviral (11), hepatoprotective (12), antioxidative (13). Emodin also has potential antitumor properties, the mechanism of which is still under investigation. Existing reports indicate that emodin is characterized by e.g. proapoptotic, prooxidative and antiangiogenic effects (1419). To our knowledge, there are no data on the effect of emodin on the lysosomal system responsible for maintaining cell homeostasis, and in specific conditions i.e. the action of reactive oxygen species, some antitumor drugs, or lysosomotropic compounds indirectly for cell death. Therefore, the purpose of this work was to evaluate the range of biochemical, ultrastructural and morphological changes in the lysosomal compartment of tumor cells exposed to emodin.

\section{Materials and Methods}

In vitro culture conditions. HeLa cell line was grown under standard culture conditions in a $\mathrm{CO}_{2}$ DirectHeat (Thermo Fisher Scientific, Waltham, MA, USA) incubator. Cells came from the Department of Radiobiology and Immunology, UJK Kielce. The cells were grown on Dulbecco's Modified Eagle's medium (Thermo Scientific) supplemented with $10 \%$ fetal bovine serum with addition of $1 \%$ 
antibiotic mixture. Emodin was purchased from Sigma-Aldrich (St. Louis, MO, USA). The cells were exposed to emodin in a concentration range of 1-100 $\mu \mathrm{M}$ for $48 \mathrm{~h}$.

Ultrastructural evaluation of cells under transmission electron microscopy. Cells were fixed in 3\% glutaraldehyde using a modified method of Marzella and Glauman (20). Secondary fixation was performed in $2 \%$ osmium tetroxide (SPI Supplies, West Chester, PA USA). The cells were immersed in Epon 812 resin (Serva Electrophoresis, Heidelberg, Germany) and polymerized. The preparations were cut on an EM UC7 ultramicrotome (Leica Microsystems, Wetzlar, Germany) and analyzed using a TECNAI G2 Spirit (FEI Company, Hillsboro, OR, USA) transmission electron microscope. Autophagic vacuoles were measured using TEM Imaging \& Analysis 3.2 SP6 software (FEI Company). Organelle size was evaluated in groups of 50 cells treated with different concentration of emodin. Average values were calculated from the obtained data.

Marking the lysosomal compartment in cells using acridine orange. The induction of lysosomal membrane permeability by emodin was analyzed by the acridine orange translocation method. This dye is a lipophilic fluorochrome which accumulates at high concentrations in lysosomes, producing red fluorescence. Deprotonated acridine orange at low concentrations in the nucleus and cytosol exhibits green fluorescence (21). Marking of lysosomes with acridine orange was carried out according to the modified Harhaji et al. method (22). Cells in basal medium (control cells) and cells in medium treated with emodin were washed with PBS and then incubated with a solution of acridine orange $(50 \mu \mathrm{g} / \mathrm{ml})$ for $15 \mathrm{~min}$. Images were made using a Nikon A1R confocal microscope (Nikon Instruments, Amsterdam, Netherlands).

Test of neutral red (NR) absorbance by lysosomes. Lysosomes were marked with a neutral red according to the modified methodology of Michalik et al. (23) using the phenomenon of NR absorption by lysosomes. The control cells and the cells with emodin were incubated with NR $(50 \mu \mathrm{g} / \mathrm{ml})$ (Sigma-Aldrich, St. Louis, MO, USA) for $3 \mathrm{~h}$ at $37^{\circ} \mathrm{C}$ and endocytosis was interrupted by washing the cells with PBS.

Enzymatic evaluation of activity of cathepsin D and L. Cells after 48 hours with emodin were trypsinized and submitted to the homogenization process. The lysosomal fraction of the cells was obtained according to the modified methodology of Marzella and Glauman (24). In the obtained lysosomal and extralysosomal fractions the activity of lysosomal cathepsin D (E.C. 3.4.23.5) and L (EC 3.4.22.15) was measured according to the method of Langner $e t$ al. (25) and the total protein content according to the method of Lowry as modified by Kirschke and Wiederanders (26). Activity of tested enzymes is expressed in $\mu \mathrm{mol} / \mathrm{mg}$ protein/hour. Measurements were made by spectrophotometric method using a Nicolet Evolution spectrophotometer (Thermo Scientific). Biochemical results are the average of three independent experiments.

Evaluation of the degree of cytotoxicity of emodin to lysosomes: NR uptake assay. Cells treated with emodin at different concentrations were supplemented with NR at $50 \mu \mathrm{g} / \mathrm{ml}$ (according to Borenfreund's and Puerner's modified method) (27) for $3 \mathrm{~h}$ at $37^{\circ} \mathrm{C}$ to ensure dye absorption by the lysosomes. Cells were fixed, then solvent (ethanol/glacial acetic acid solution) was added in order to release the NR absorbed by the cells, with extraction for $10 \mathrm{~min}$ on a microplate shaker. The absorbance values were read at $540 \mathrm{~nm}$ and $690 \mathrm{~nm}$ on a Synergy 2 multimode microplate reader (BioTek, Winooski, VT, USA). The test was repeated in three independent experiments.

Visualization of apoptosis in cells: 4',6-Diamidine-2-phenylindole (DAPI) staining. Evaluation of apoptosis in cells after administration of the test compound was made using a fluorescent marker (DAPI) to detect nuclear condensation and fragmentation. HeLa cells were cultured for 48 hours in medium with emodin $(100 \mu \mathrm{M})$ or without (control cells). The culture medium was removed, $10 \mu \mathrm{g} / \mathrm{ml}$ DAPI solution (Sigma-Aldrich) was added and the cells were incubated for 15 minutes. Cells were then washed in PBS and analyzed in terms of morphological changes in nucleus under a Nikon Eclipse 80i fluorescence microscope (Nikon Instruments, Amsterdam, Netherlands).

Statistical analysis. The results of the study were analyzed using analysis of variance (ANOVA). Analyses of cell viability and evaluation of changes in lysosomal enzyme activity were performed using the Tukey test. Results of morphometric measurements of autophagic vacuoles were assessed using the Kruskal-Wallis nonparametric test. The differences were statistically significant at $p<0.05$.

\section{Results}

Growth of degradation processes in HeLa cells induced by emodin. Even at a concentration of $1 \mu \mathrm{M}$ emodin, changes appeared compared with the control (Figure 1A) indicating an increase in biosynthesis, which is manifested by swelling of Golgi apparatus cisternae and enlargement of channels of the rough endoplasmic reticulum (Figure 1B). As the concentration of emodin increased, increase in degradation processes was induced, as indicated by the intense accumulation of a very large number of secondary lysosomes (Figure 1D) and autophagic vacuoles at various stages of formation (Figure 1C). They were limited by a double membrane, derived from rough endoplasmic reticulum (Figure 1E). They contained material at varying degrees of digestion (Figure 1F), often strongly degraded and electrondense (Figure 1G). There was also a statistically significant increase in the size of vacuoles with increasing emodin concentration (Figure 2). As the concentration of emodin increased, there was also a progressive reduction in the cisternae of the Golgi apparatus and the rough endoplasmic reticulum (Figure 1F). Numerous and very swollen mitochondria, with a clear matrix with damaged cristae, and cells in late-stage apoptosis showing disintegration into numerous apoptotic bodies containing, e.g. nuclear fragments, (Figure $1 \mathrm{H}$ ) were also apparent.

Increase in the number of lysosomes and autophagic vacuoles induced by emodin. Cells exposed to emodin at $1 \mu \mathrm{M}$ showed a stimulatory effect on the activity of the lysosomal system reflected by an increase in the number of lysosomes that absorbed neutral red (Figure 3B). Emodin at a concentration 

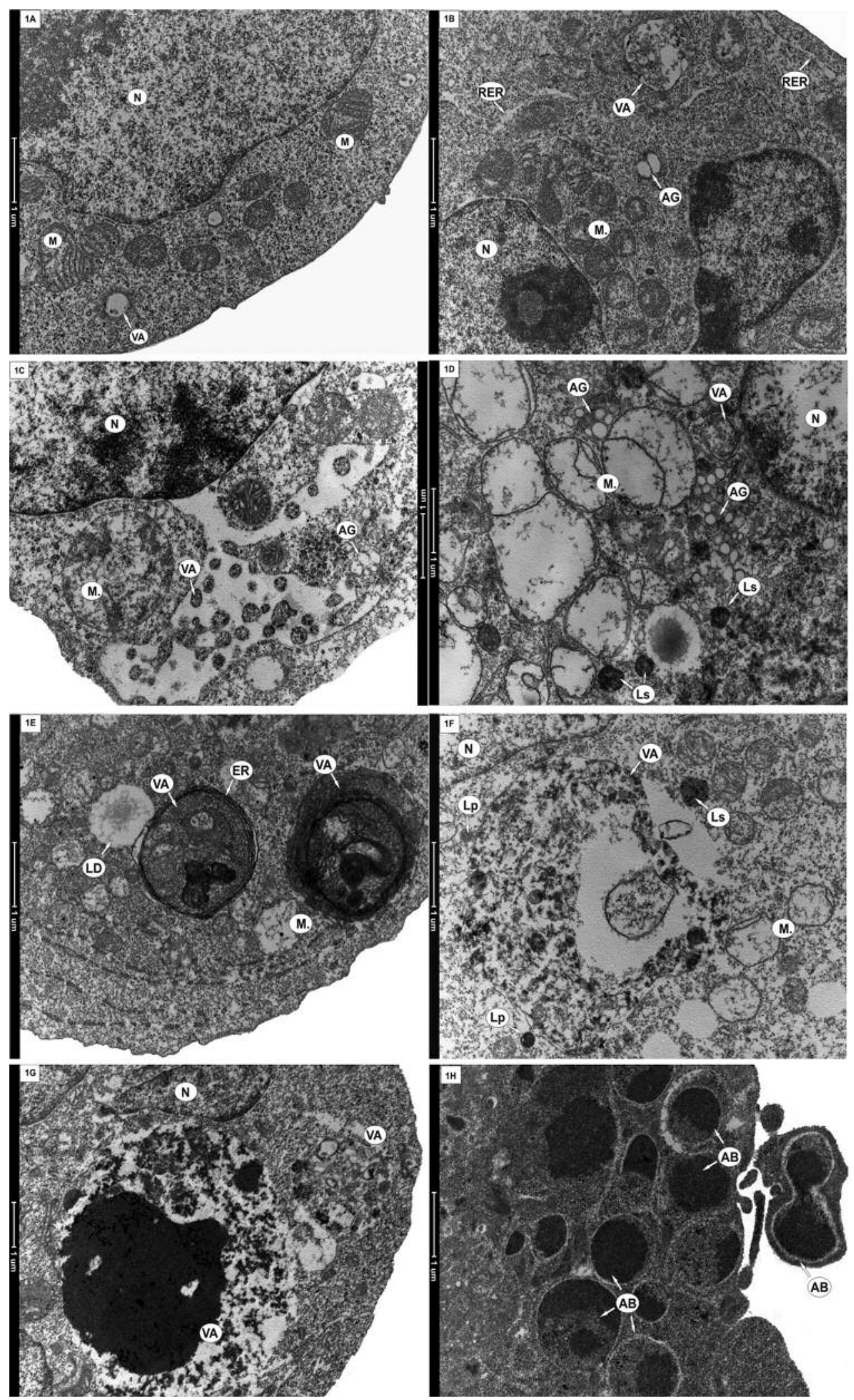

Figure 1. Ultrastructure of HeLa cells after 48-h incubation in basal medium (control; A) and when exposed to different concentrations of emodin: $1 \mu M(B), 15 \mu M(C), 30 \mu M(D), 45 \mu M(E), 60 \mu M(F)$ and $100 \mu M(G, H)$. Magnification $\times 16,500$. Nucleus $(N)$, mitochondria $(M)$, Golgi apparatus $(A G)$, autophagic vacuoles $(V A)$, primary $(L p)$ and secondary $(L s)$ lysosomes, and apoptotic bodies $(A B)$ are visible in the cytoplasm. 


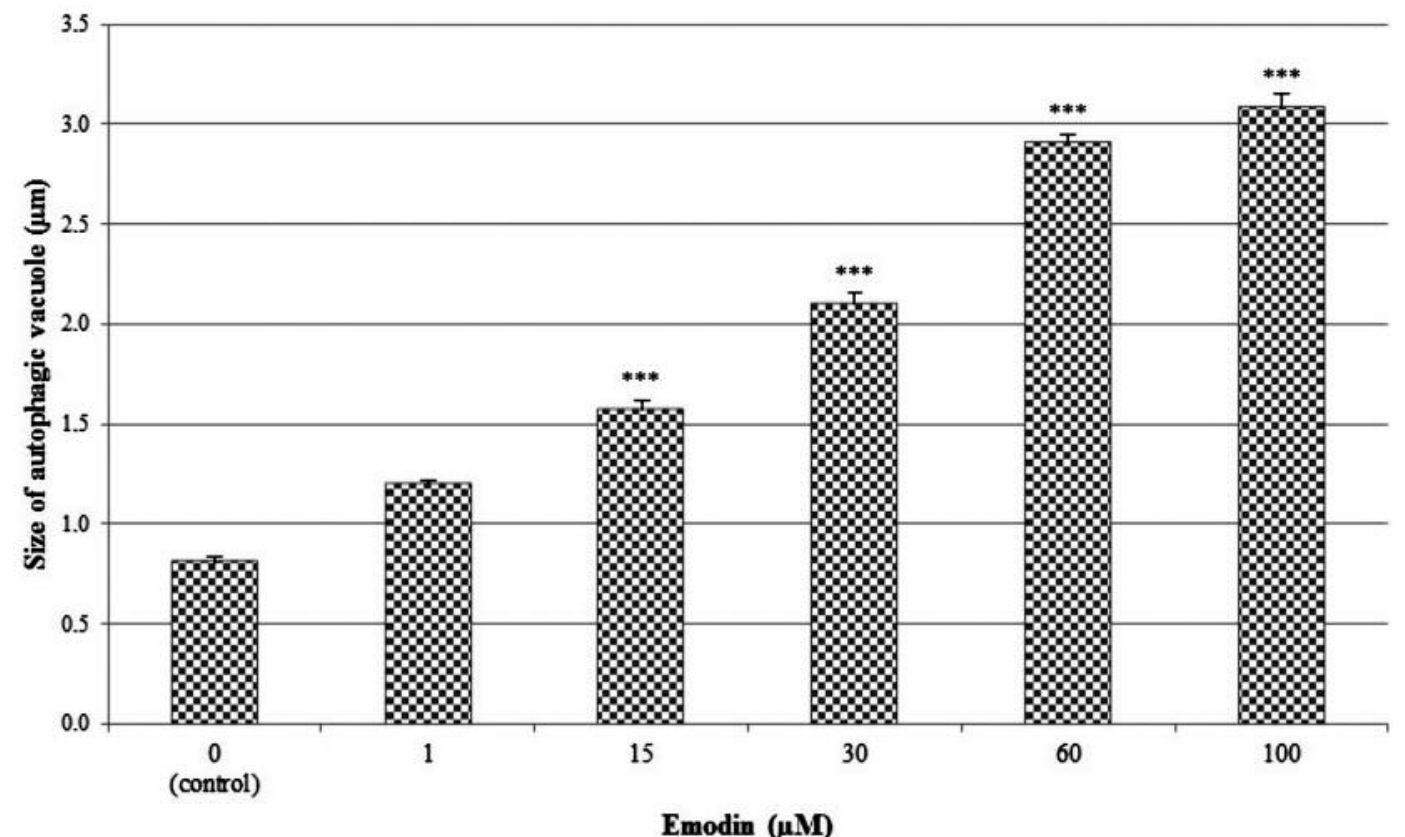

Figure 2. Changing size of autophagic vacuoles in HeLa cells after 48-h exposure to different concentrations of emodin. Results are the mean \pm SD of 50 counted cells (for each group). Differences were confirmed to be statistically significant at: $* * * p<0.001$.

range of $15-30 \mu \mathrm{M}$ caused significant activation of the lysosomal system in the form of the presence of very numerous lysosomes and numerous small cytoplasmic vacuoles (Figure $3 \mathrm{C}$ and D). A concentration of $60 \mu \mathrm{M}$ emodin induced an increased number of cytoplasmic vacuoles and autophagic vacuoles containing large amounts of absorbed dye (Figure 3E). The highest range of changes was demonstrated in cells incubated with emodin at $100 \mu \mathrm{M}$, where few lysosomes and vacuoles and very numerous apoptotic cells were revealed (Figure 3F).

Increase of permeabilization of lysosomal membrane depends on the concentration of emodin. At a concentration of $1 \mu \mathrm{M}$ emodin, numerous lysosomes and cells with cytoplasmic vacuolization were observed (Figure 4B). Cells exposed to 15 and $30 \mu \mathrm{M}$ emodin were characterized by the highest intensification of red fluorescence. This indicates a significant increase in the activity of the lysosomal system, expressed by an increase in the number of lysosomes and vacuoles (Figure $4 \mathrm{C}$ and D). Cell exposure to emodin at a concentration of 60 $\mu \mathrm{M}$ resulted in visible fluorescent color saturation of the cytoplasmic degradation site, i.e. in autophagic vacuoles, as well as the presence of cells with gradual suppression of fluorescent color in lysosomes (Figure 4E). The highest used concentration $(100 \mu \mathrm{M})$ of emodin induced significant gradual of emission of orange fluorescence in the marked, very sparse lysosomes (Figure 4F).
Change in cathepsin $D$ and L activity is dependent on the concentration of emodin. Incubation of cells with emodin led to increased lysosomal membrane permeability, resulting in a highly statistically significant decrease in cathepsin D and L activity in the lysosomal fraction, while the extralysosomal fraction was characterized by a highly statistically significant increase in the activity of proteolytic enzymes (Figure 5).

The cytotoxic effect of emodin on lysosomes of tumor cells (NR test). From the lysosomal NR uptake assay, emodin was found to statistically significant reduce cell viability (Figure 6). A $50 \%$ reduction in viability $\left(\mathrm{IC}_{50}\right)$ in the examined cells was demonstrated to occur at an emodin concentration of $39.084 \mu \mathrm{M}$. A 48-h exposure to $80 \mu \mathrm{M}$ of emodin caused a further disturbance of lysosomal membrane integrity, resulting in a decrease in cell viability to $15.86 \%$. Reduction in HeLa cell viability of $90 \%\left(\mathrm{IC}_{90}\right)$ was demonstrated at an emodin concentration of $93.814 \mu \mathrm{M}$.

Induction of apoptosis in HeLa cells is enhanced by emodin. HeLa cells exposed to emodin at $100 \mu \mathrm{M}$ for $48 \mathrm{~h}$ clearly exhibited apoptosis (imaging by DAPI staining). Dying nuclei of cells resulted in an increase in the number of nuclei exhibiting specific symptoms characteristic of apoptosis, such as the chromatin condensation and nuclear fragmentation seen in Figure 7B. 


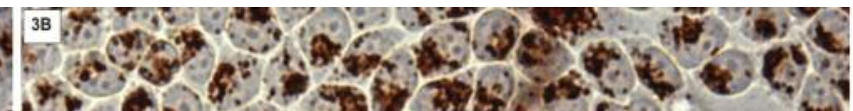

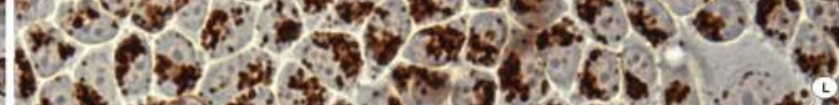
(a) $A$ a

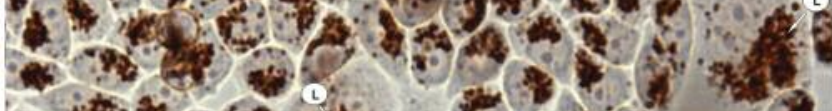

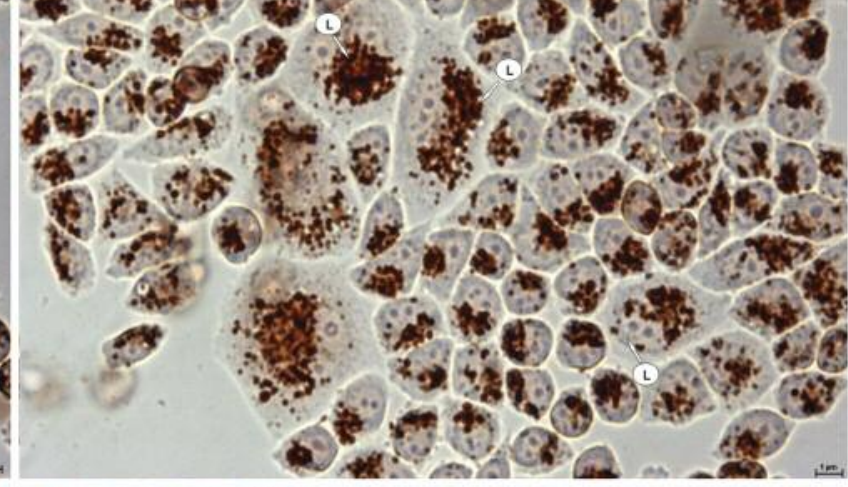

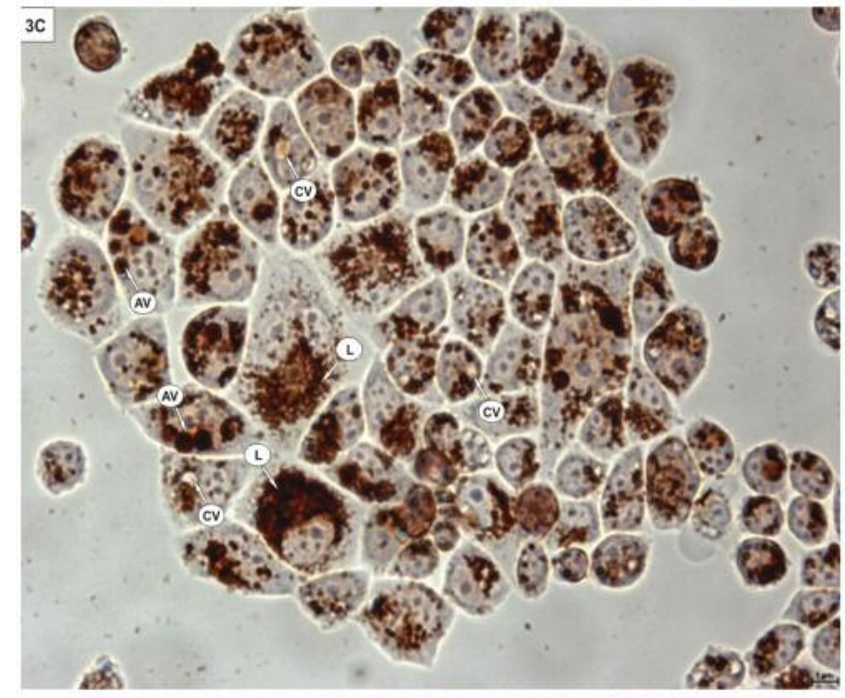

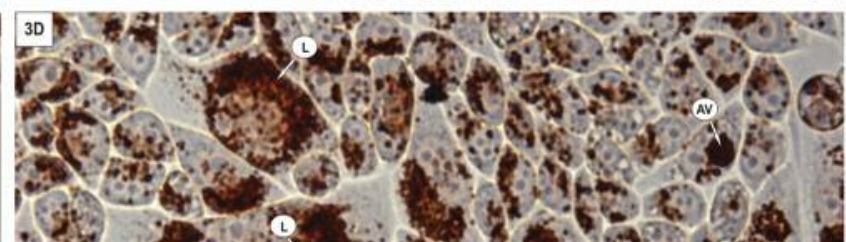
(A.

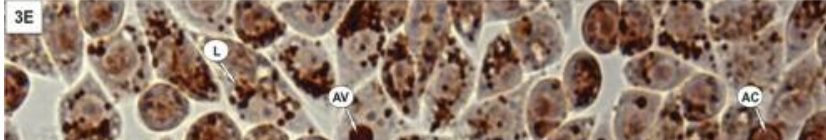

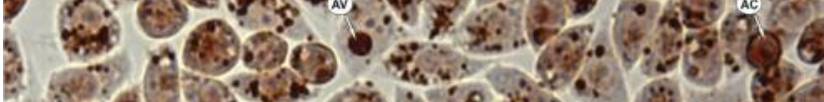

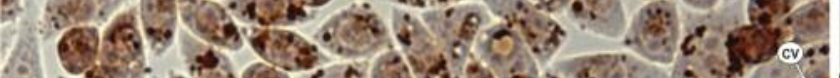

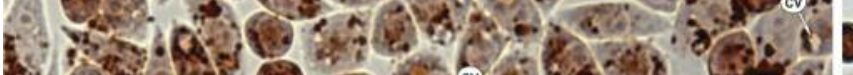

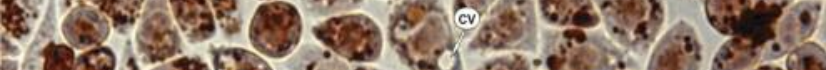

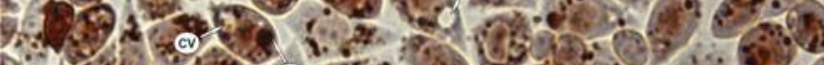
ac 0 (av

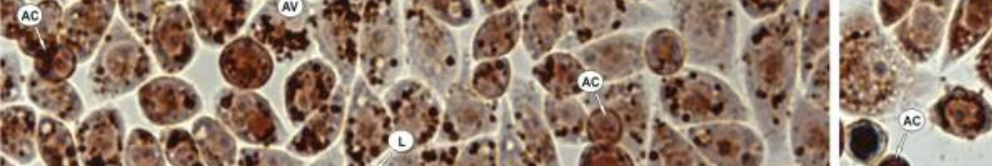

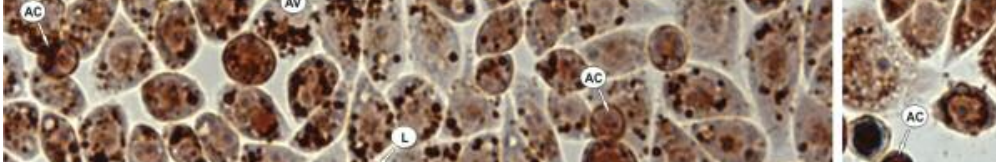

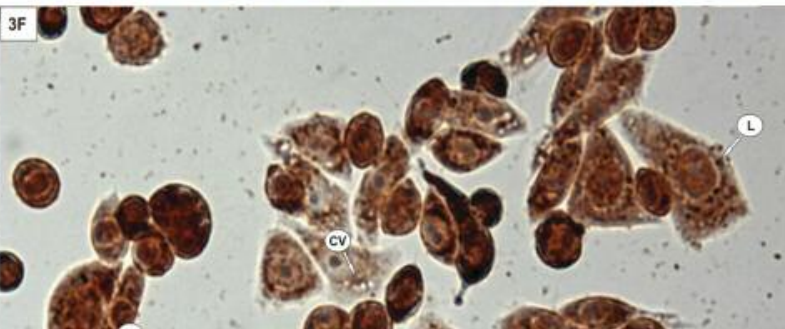

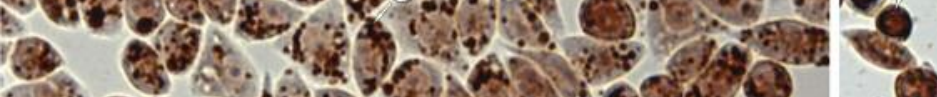

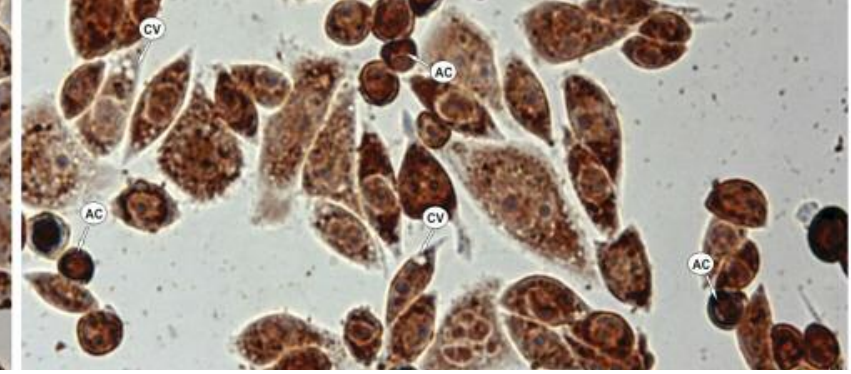

Figure 3. HeLa cells after 48-h incubation in basal medium (control; A) and when exposed to different concentrations of emodin: $1 \mu M(B), 15 \mu M$ $(C), 30 \mu M(D), 60 \mu M(E)$ and $100 \mu M(F)$. Cells were dyed with neutral red: lysosomes $(L)$, cytoplasmic vacuoles $(C V)$, autophagic vacuoles $(A V)$, and apoptotic cells $(A C)$ can be clearly seen. Magnification $\times 4,000$. 

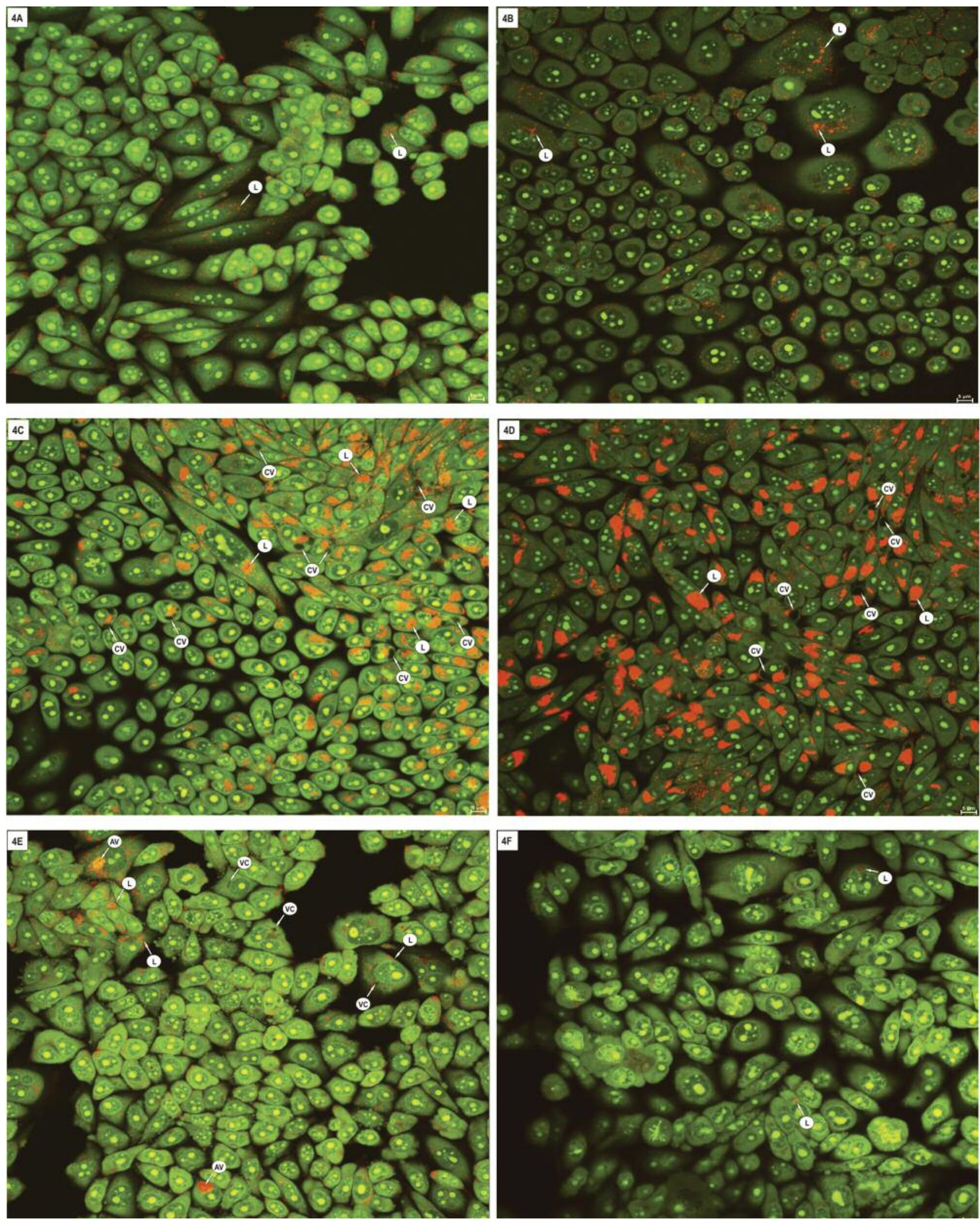

Figure 4. HeLa cells after 48-h incubation in basal medium (control; $A)$ and when exposed to different concentrations of emodin: $1 \mu M(B), 15 \mu M(C)$, $30 \mu M(D), 60 \mu M(E)$ and $100 \mu M(F)$. Cells were stained with acridine orange: lysosomes $(L)$ (red emission), autophagic vacuoles (VA), cytoplasmic vacuoles (VC) are clearly visible. Green fluorescence of cytoplasm. Magnification ×4,000. 


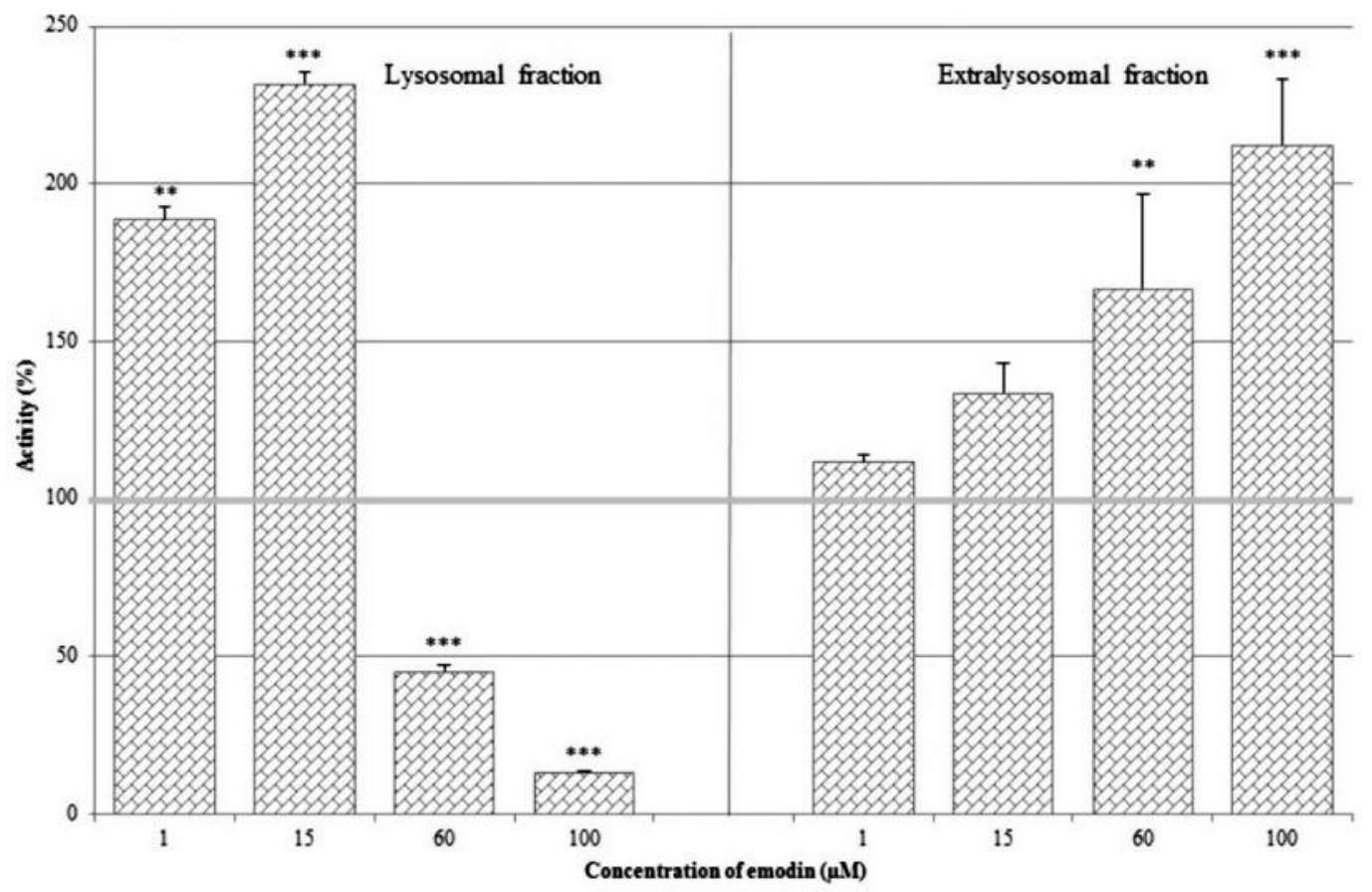

Figure 5. Activity (mean $\pm S D$ ) of cathepsin $D$ and $L$ in the lysosomal and extralysosomal fraction of HeLa cells after 48 h of exposure to different concentrations of emodin. Differences were confirmed to be statistically significant at: $* * p<0.01 ; * * * p<0.001$.

\section{Discussion}

Despite the intensive development of medical research, cancer is currently the second leading cause of death in humans $(28,29)$. The main weakness of anticancer therapy is the phenomenon of cellular resistance to cytostatics. One goal of modern medicine is to find new strategies which would allow the resistance of tumor cells to the therapies used to be overcome, and to discover the mechanisms leading to the development of such resistance, including multidrug resistance $(30,31)$. The development of cell resistance to chemotherapy involves, e.g. reduction of drug penetration into the cell and drug transport between the cell nucleus and cytoplasm, activation of detoxification systems, activation of DNA repair mechanisms, and the ability of tumor cells to disrupt the regulation of drug-induced apoptosis (30-32). Resistance of cancer cells, both initial and acquired, to commonly used chemotherapeutics is a serious problem in the treatment of cancer (32). Hence, there is a constant search for new antitumor compounds that have the ability to induce different mechanisms leading to cell death, including lysosomes, with emodin being an example of such compounds. The present study found that this compound modulates the activation and differentiation of the lysosomal compartment of HeLa cells, as evidenced by the emodin concentration-dependent increase in the number of NR
(Figure 3C and D) and acridine orange (Figure 4C and D) labelled lysosomes, as well as by vacuoles packed with highly degraded material (Figure 1E-G). The induction of autophagic processes occurring in the examined tumor cells is also confirmed by the morphometric measurements (Figure 2), which at a $100 \mu \mathrm{M}$ concentration showed a statistically significant increase in the dimensions of autophagic vacuoles (by $282 \%$ ) relative to the vacuole volume in the control cells. The demonstrated reduction of rough endoplasmic reticulum and cisternae of the Golgi apparatus (Figure 1F) additionally indicates that a macroautophagy process was occuring, in which the membranes of these organelles can be used to surround the degraded material $(33,34)$.

From the available literature, it appears that standard anticancer drugs, e.g. taxol, vinblastine, vincristine and colchicine, also have the ability to induce and modulate the process of autophagy (35-42) which makes emodin similar in terms of mechanism of action. The induction of autophagy in tumor cells is, as the literature suggests, a desirable form of cancer treatment strategy, especially when cells are resistant to apoptosis $(43,44)$.

Studies show that pro-apoptotic effects of emodin are not only related to the mitochondrial pathway (14-19), but also to the lysosomal system. The application of emodin in a concentration of $60 \mu \mathrm{M}$ and $100 \mu \mathrm{M}$ resulted in nearly 


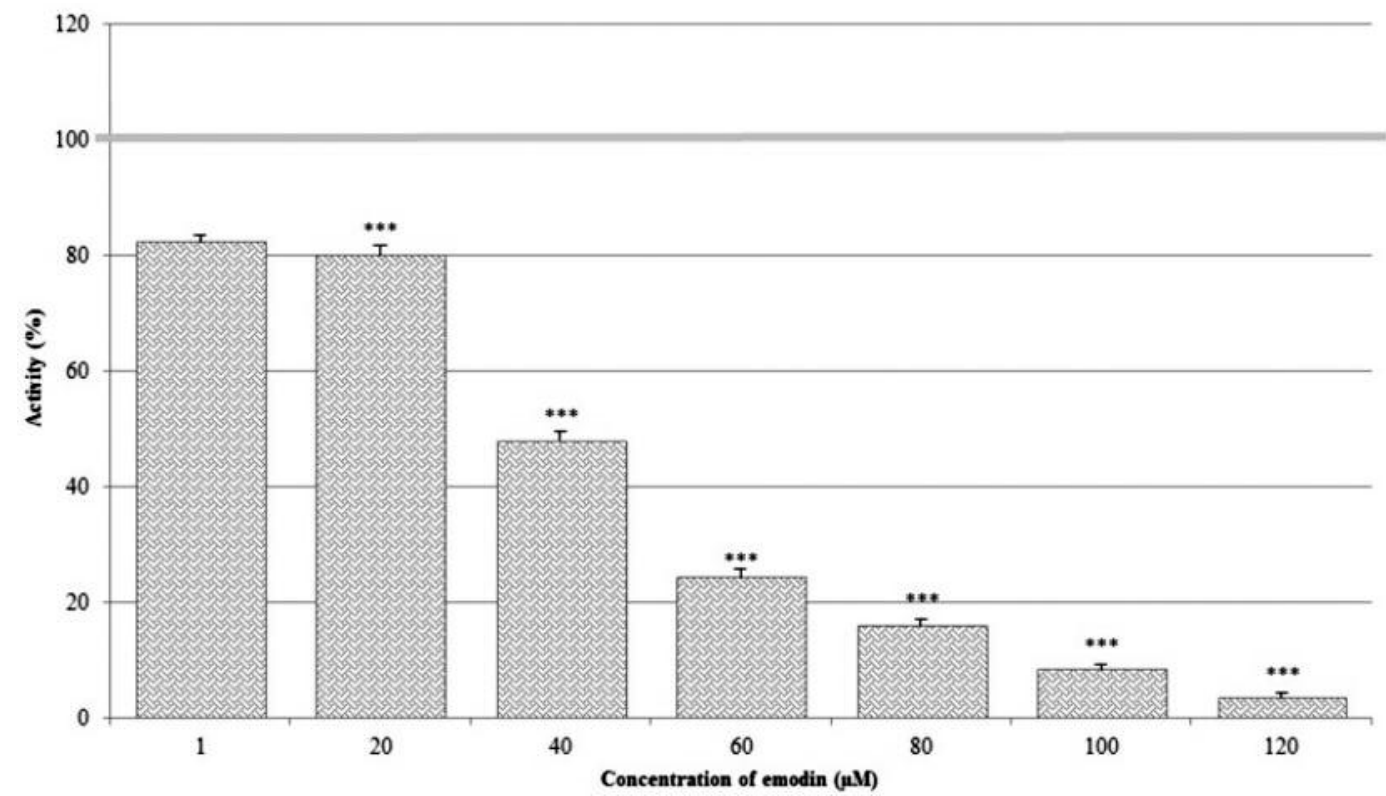

Figure 6. HeLa cell viability determined by neutral red (NR) uptake assay after 48-h exposure to different concentrations of emodin. Differences were confirmed to be statistically significant at: ${ }^{* * *} p<0.001 . I C_{50} / I C_{90}: 39.08 \pm 0.86 \mu M / 93.81 \pm 0.75 \mu M$.

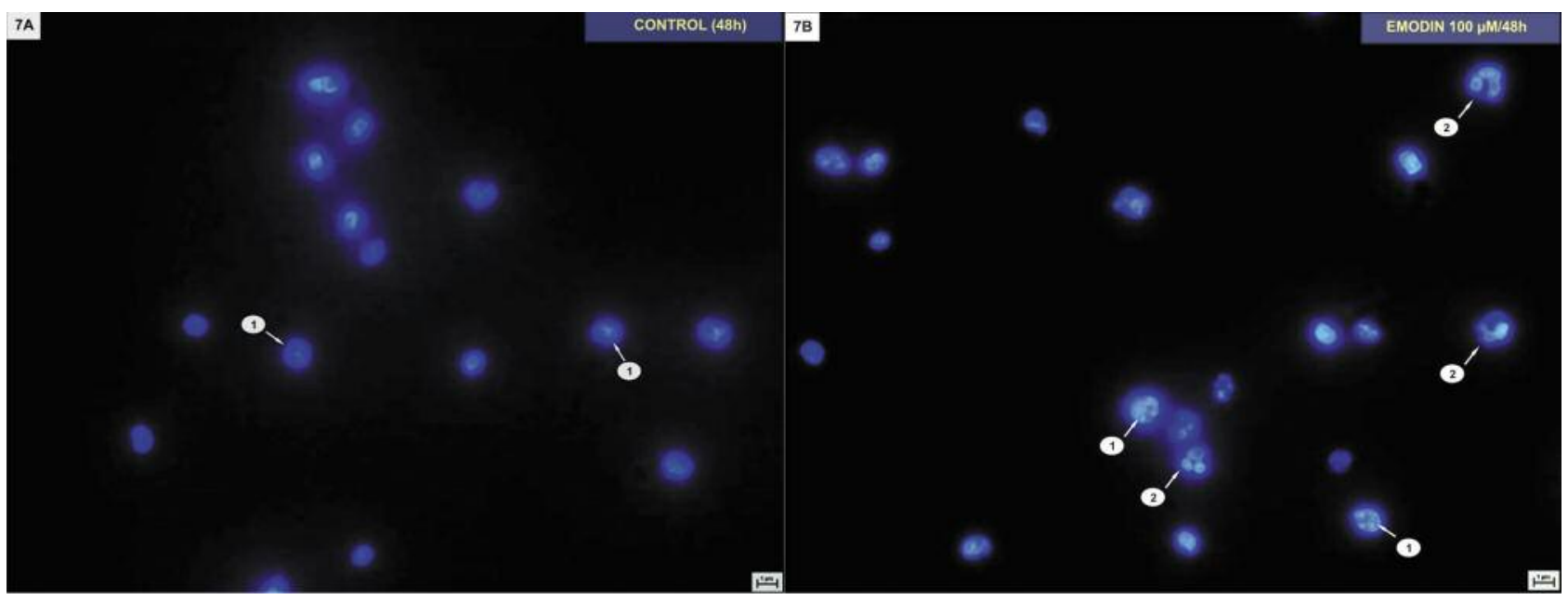

Figure 7. Apoptosis observed in HeLa cells using 4',6-Diamidine-2-phenylindole staining. Cells were exposed or not to emodin at $100 \mu \mathrm{M}$ for 48 h. Control cells (not exposed to the test agent) showed normal nuclear morphology (A). Cells exposed to emodin showed chromatin condensation (CC) and nuclear fragmentation $(N F)(B)$. Magnification $\times 400$.

complete suppression of the red fluorescent orange acridine (Figure 4E). This indicates an emodin-dependent damage to the lysosomal membrane, which is the point of accumulation of the indicator used. Acridine orange is a non-enzymatic marker of lysosomal permeability and its intensity is directly proportional to the degree of acidity and volume of the lysosomal compartment $(21,45)$. Moreover, the NR test showed that when high concentrations of emodin were used, absorption of NR by lysosomes was inhibited (Figure 6). This confirms the increased permeability of the lysosomal membrane with possible leaks of lysosomal hydrolases into the cytoplasm of the cell, which has also been demonstrated 
in biochemical studies (Figure 5). This may indicate high accumulation of emodin in lysosomes and induction of apoptotic processes in tumor cells (Figures 1H, 3F, 7B) with a lysosomal compartment.

Cathepsins are proteolytic enzymes, commonly thought to be the cell death indicator released from lysosomes as a consequence of their membrane damage (46). Leakage of the lysosomal membrane may be a potentially lethal event for tumor cells because the presence of lysosomal proteases in the cytosol can cause digestion of important cellular proteins and the activation of additional enzymes, including of caspases $(21,47)$, thus inducing caspase-dependent apoptosis.

\section{Conclusion}

The results show that emodin induces degradation processes in the studied tumor cells. Emodin at high concentrations was also cytotoxic against lysosomes. Destabilizing lysosomal membranes caused increased lysosomal permeability and cathepsin leakage into the cytoplasm, inducing apoptosis. The demonstrated induction of autophagy and apoptosis involving the lysosomal compartment in cervical cancer cells may indicate an additional mechanism of anticancer action of emodin.

\section{Conflicts of Interest}

All Authors have read the Journal's policy on disclosure of potential conflicts of interest and have none to declare.

\section{Acknowledgements}

This work was supported by Jan Kochanowski University, grant: 066/R/11.

\section{References}

1 Hanahan D and Weinberg RA: The hallmarks of cancer. Cell 100: 57-70, 2000

2 Kroemer G and Jäättelä M: Lysosomes and autophagy in cell death control. Nat Rev Cancer 5: 886-897, 2005.

3 Rammer P, Groth-Pedersen L, Kirkegaard T, Daugaard M, Rytter A, Szyniarowski P, Høyer-Hansen M, Povlsen LK, Nylandsted J, Larsen JE and Jäättelä M: BAMLET activates a lysosomal cell death program in cancer cells. Mol Cancer Ther 9: 24-32, 2010.

4 Yang ZJ, Chee ChE, Huang S and Sinicrope FA: Autophagy modulation for cancer therapy. Cancer Biol Ther 11: 169-176, 2011.

5 De La Rue W and Treas FRS, Müller H: On some constituents of rhubarb. Q J Chem Soc 10: 298-307, 1858.

6 Choi S and Chung MH: A review on the relationship between Aloe vera components and their biologic effects. Semin Integr Med 1: 53-62, 2003.

7 Cui YT, Liu B, Xie J, Xu P, Habte-Tsion HM and Zhang YY: The effect of emodin on cytotoxicity, apoptosis and antioxidant capacity in the hepatic cells of grass carp (Ctenopharyngodon idellus). Fish Shellfish Immunol 38: 74-79, 2014.
8 Huang HC, Chang JH, Tung SF, Wu RT, Foegh ML and Chu $\mathrm{SH}$ : Immunosuppressive effect of emodin, a free radical generator. Eur J Pharmacol 211: 359-64, 1992.

9 Chukwujekwu JC, Coombes PH, Mullholand DA and Van Staden J: Emodin, an antibacterial anthraquinone from the roots of Cassia occidentaliss. S Afr J Bot 72: 295-297, 2006.

10 Kremer D, Kosalec I, Locatelli M, Epifano F, Genovese S, Carlucci $G$ and Zovko Končić M: Anthraquinone profiles, antioxidant and antimicrobial properties of Frangula rupestris (Scop.) Schur and Frangula alnus Mill. Bark Food Chem 131: 1174-1180, 2012.

11 Xiong HR, Luo J, Hou W, Xiao H and Yang ZQ: The effect of emodin, an anthraquinone derivative extracted from the roots of Rheum tanguticum, against herpes simplex virus in vitro and in vivo. J Ethnopharmacol 133: 718-23, 2011.

12 Lee BH, Huang YY, Duh PD and Wu SC: Hepatoprotection of emodin and Polygonum multiflorum against $\mathrm{CCl}(4)$-induced liver injury. Pharm Biol 3: 351-9, 2012.

$13 \mathrm{Du} \mathrm{Y}$ and Ko KM: Effects of emodin treatment on mitochondrial ATP generation capacity and antioxidant components as well as susceptibility to ischemia-reperfusion injury in rat hearts: Single versus multiple doses and gender difference. Life Sci 77: 27702782, 2005.

14 Chen YC, Shen SC, Lee WR, Hsu FL, Lin HY, Ko CH and Tseng SW: Emodin induces apoptosis in human promyeloleukemic HL-60 cells accompanied by activation of caspase 3 cascade but independent of reactive oxygen species production. Biochem Pharmacol 64: 1713-1724, 2002.

15 Chun-Guang W, Jun-Qing Y, Bei-Zhong L, Dan-Ting J, Chong W, Liang Z, Dan Z and Yan W: Anti-tumor activity of emodin against human chronic myelocytic leukemia K562 cell lines in vitro and in vivo. Eur J Pharmacol 627: 33-41, 2010.

16 Lee HZ: Protein kinase $\mathrm{C}$ involvement in aloe-emodin and emodin-induced apoptosis in lung carcinoma cell. $\mathrm{Br} \mathrm{J}$ Pharmacol 134: 1093-1103, 2001.

17 Jing X, Ueki N, Cheng J, Imanishi H and Hada T: Induction of apoptosis in hepatocellular carcinoma cell lines by emodin. Jpn J Cancer Res 93: 874-882, 2002.

18 Lin SY, Lai WW, Ho ChCh, Yu FS, Chen GW, Yang JS, Liu $\mathrm{KCh}$, Lin ML, Wu PP, Fan MJ and Chung JG: Emodin induces apoptosis of human tongue squamous cancer SCC-4 cells through reactive oxygen species and mitochondria-dependent pathways. Anticancer Res 29: 327-336, 2009.

19 Huang Z, Chen G and Shi P: Emodin-induced apoptosis in human breast cancer BCap-37 cells through the mitochondrial signaling pathway. Arch Pharm Res 31: 742-748, 2008.

20 Marzella L and Glaumann $\mathrm{H}$ : Increased degradation In rat liver induced by vinblastine. II. Morphological characterization. Lab Invest 42: 18-27, 1980.

21 Boya P and Kroemer G: Lysosomal membrane permeabilization in cell death. Oncogene 27: 6434-6451, 2008.

22 Harhaji L, Isakovic A, Raicevic N, Markovic Z, TodorovicMarkovic B, Nikolic N, Vranjes-Djuric S, Markovic I and Trajkovic V: Multiple mechanisms underlying the anticancer action of nanocrystalline fullerene. Eur J Pharmacol 568: 89-98, 2007.

23 Michalik M, Pierzchalska M, Pabiańczyk-Kulka A and Korohoda W: Procaine-induced enhancement of fluid-phase endocytosis and inhibition of exocytosis in human skin fibroblasts. Eur J Pharmacol 475: 1-10, 2003. 
24 Marzella L and Glaumann H: Increased degradation in rat liver induced by vinblastine. I. Biochemical characterization. Lab Invest 42: 8-17, 1980.

25 Langner J, Wakil A, Zimmermann M, Ansorge S, Bohley P, Kirschke $\mathrm{H}$ and Wiederanders $\mathrm{B}$ : Aktivitätsbestimmung proteolytischer Enzyme mit Azokasein als Substrat. Acta Biol Med Ger 31: 1-18, 1973.

26 Kirschke $\mathrm{H}$ and Wiederanders B: Methoden zur Aktivitätsbestimmung von Proteinasen. Martin-Luther-Universität Halle-Wittenberg Wissenschaftliche Beitrage Halle/Salle pp. 1117, 1984.

27 Borenfreund E and Puerner JA: Toxicity determined in vitro by morphological alterations and neutral red absorption. Toxicol Lett 24: 119-124, 1985.

28 Torre LA, Bray F, Siegel RL, Ferlay J, Lortet-Tieulent J and Jemal A: Global cancer statistics. CA Cancer J Clin 65: 87-108, 2012.

29 Siegel RL, Miller KD and Jemal A: Cancer statistics. CA Cancer J Clin 66: 7-30, 2016.

30 Gillet JP and Gottesman MM: Mechanisms of multidrug resistance in cancer. Methods Mol Biol 596: 47-76, 2010.

31 Gottesman MM: Mechanisms of cancer drug resistance. Annu Rev Med 53: 615-627, 2002.

32 Zahreddine $\mathrm{H}$ and Borden KLB: Mechanisms and insights into drug resistance in cancer. Front Pharmacol 4: 1-8, 2013.

33 Geng $\mathrm{J}$ and Klionsky DJ: The Golgi as a potential membrane source for autophagy. Autophagy 6: 950-951, 2010.

34 Mijaljica D, Prescott M and Devenish RJ: Endoplasmic reticulum and Golgi complex: Contributions to and turnover by, autophagy. Traffic 7: 1590-1595, 2006.

35 Aredia F, Ortiz LMG, Giansanti V and Scovassi AI: Autophagy and cancer. Cells 1: 520-534, 2006.

36 Janku F, McConkey DJ, Hong DS and Kurzrock R: Autophagy as a target for anticancer therapy. Nat Rev Clin Oncol 8: 528-39, 2011.

37 Esteve JM and Knecht E: Mechanisms of autophagy and apoptosis: Recent developments in breast cancer cells. World J Biol Chem 2: 232-238, 2011.
38 Wang XP, Chen TS, Sun L, Cai JY, Wu MQ and Mok M: Live morphological analysis of taxol-induced cytoplasmic vacuolization in human lung adenocarcinoma cells. Micron 39: 1216-21, 2008

39 Król T, Schmidt M, Kołątaj A and Witek B: Vinblastine-induced autophagy in mouse liver. Comp Biochem Physiol Pharmacol Toxicol Endocrinol 107: 165-169, 1994.

40 Król T: Vincristine-induced autophagy in mouse liver. Acta Biol Cracov series Zool 38: 5-8, 1996.

$41 \mathrm{Kró}$ T: Influence of colchicine on autodegradation in mouse hepatocytes. Acta Biol Cracov series Zool 40: 31-39, 1998.

42 Król T: Activity of lysosomal system in mouse liver after taxol administration. Gen Pharmac 30: 239-243, 1998.

43 Liu B, Bao JK, Yang JM and Cheng Y: Targeting autophagic pathways for cancer drug discovery. Chin J Cancer 32: 113-120, 2013.

44 Mathew R: Role of autophagy in cancer. Nat Rev Cancer 7: 961967, 2007.

45 Paglin S, Hollister T, Delohery T, Hackett N, McMahill M, Sphicas E, Domingo D and Yahalom J: A novel response of cancer cells to radiation involves autophagy and formation of acidic vesicles. Cancer Res 61: 439-444, 2001.

46 Mrschtik M and Ryan KM: Lysosomal proteins in cell death and autophagy. FEBS Journal 282: 1858-1870, 2015.

47 Guicciardi ME, Leist M and Gores GJ: Lysosomes in cell death. Oncogene 23: 2881-2890, 2004. 